\title{
Sistem Pendukung Keputusan Seleksi Beasiswa Prestasi Miskin Dengan Metode Composite Performance Index (CPI)
}

\author{
Bahrin $^{1 *}$, Betrisandi ${ }^{2}$, dan Maryam Diange ${ }^{3}$ \\ ${ }^{1,2}$ Universitas Pohuwato \\ Jln. Trans Sulawesi No. 147 Marisa Kab. Pohuwato, Marisa 96266 \\ ${ }^{3}$ Universitas Ichsan Gorontalo \\ Jl. Trans Sulawesi Marisa Buntulia, 96266 \\ *e-mail:bahrindahlan@gmail.com
}

\begin{abstract}
Abstrak - Banyaknya jumlah mahasiswa yang mengajukan beasiswa prestasi miskin ke Dinas Pendidikan Kabupaten Pohuwato serta indicator kriteria yang banyak juga, maka perlu dibangun sebuah system pendukung keputusan yang akan membantu penentuan siapa yang berhak untuk mendapatkan beasiswa miskin tersebut. Beasiswa prestasi miskin merupakan program daerah yang berada di Dinas Pendidikan menjadi salah satu jenis program yang dapat dipilih oleh masyarakat secara demokratis pada musyawarah desa dan musyawarah antar desa di Dinas Pendidikan yang diperuntukkan bagi mahasiswa dari rumah tangga miskin, yang pemberiannya setiap tahun setelah ada usulan dari masing-masing desa ke Dinas Pendidikan. Tujuan dari pemberian beasiswa tersebut adalah untuk mempercepat upaya peningkatan kualitas sumber daya manusia dengan menitik beratkan pada pemerataan kesempatan pendidikan, peningkatan kualitas pendidikan, dan peningkatan kapasistas rumah tangga miskin perdesaan sebagai bagian dari upaya mempercepat penuntasan kemiskinan. Dalam hal ini metode yang digunakan yaitu metode Composite Performance Index (CPI. Berdasarkan atas hasil pengujian white box disimpulkan bahwa sistem pendukung keputusan ini bebas dari kesalahan program dengan total Cyclomatic Complexity $=5$, Region $=5$, dan Independent Path $=5$.

Kata kunci: SPK, Beasiswa Prestasi Miskin, Composite Performance Index, PHP, MySQL
\end{abstract}

Abstract- The large number of students applying for poor achievement scholarships to the Pohuwato District Education Office and a large number of criteria indicators also needs to be built in a decision support system that will help determine who is entitled to get the poor achievement scholarships. Poor achievement scholarships is a regional program in the Department of Education being one of the types of programs that can be democratically selected by the community in village meetings and inter-village meetings in the Department of Education which is intended for students from poor households, who give it every year after there proposals from each village to the Department of Education. The purpose of the scholarships is to accelerate efforts to improve the quality of human resources by focusing on equal distribution of educational opportunities, improving the quality of education, and increasing the capacity of rural poor households as part of efforts to accelerate poverty reduction. In this method used is the method of Composite Performance Index (CPI). Based on the results of the white box test, it was concluded that the decision support system was free from program errors with total Cyclomatic Complexity $=5$, Region = 5, and Independent Path = 5.

Keywords : SPK, Poor Achievement Scholarships, Composite Performance Index, PHP

\section{Pendahuluan}

Beasiswa adalah pemberian berupa bantuan keuangan yang di berikan kepada perorangan yang bertujuan untuk digunakan demi keberlangsungan pendidikan yang ditempuh. Beasiswa dapat diberikan oleh lembaga pemerintah, perusahaan ataupun yayasan[1]. Sedangkan dalam pengertian lain beasiswa yaitu dalam bentuk bantuan keuangan yang diberikan kepada individu yang bertujuan untuk digunakan demi pendidikan berkelanjutan. Beasiswa dapat diberikan oleh lembaga pemerintah, perusahaan, atau yayasan[2].

Meskipun telah ada cara penilaian tersendiri yang digunakan pada Kantor Dinas Pendidikan Kabupaten Pohuwato, tetapi cara penilaian itu masih terdapat kekurangan yang menyebabkan para petugas pada bagian pemeriksaan berkas mengalami kesulitan, dikarenakan para petugas pemeriksa berkas harus menilai dan memverifikasi bagi pemohon Beasiswa Prestasi Miskin yang cukup banyak memasukkan berkas ke Dinas Pendidikan Kabupaten Pohuwato. Banyaknya jumlah mahasiswa yang mengajukan beasiswa prestasi miskin ke Dinas Pendidikan Kabupaten Pohuwato serta indikator kriteria yang banyak juga, maka perlu di bangun sebuah sistem pendukung keputusan yang akan membantu penentuan siapa yang berhak untuk mendapatkan beasiswa prestasi miskin tersebut.

Dalam hal ini, metode yang dipakai pada sistem pendukung keputusan yaitu metode Composite Performance Index (CPI). Dalam metode CPI menggunakan pemecahan masalah dengan sistem Multiple Criteria Decision Making (MCDM) yang menentukan urutan atau prioritas dalam analisis multikriteria. Hasil 
akhir dari penelitian ini adalah terciptanya sistem pendukung keputusan yang menghasilkan informasi yang dapat dijadikan tempat referensi untuk tetap memperhatikan beberapa kriteria[3].

Berdasarkan latar belakang di atas, menjadi suatu motivasi bagi penulis untuk melakukan penelitian lebih lanjut mengenai penentuan sistem pendukung keputusan yang akan diimplementasikan pada Dinas Pendidikan Kabupaten Pohuwato. Kemudian penelitian ini berjudul "Sistem Pendukung Keputusan Seleksi Beasiswa Prestasi Miskin Dengan Metode Composite Performance Index (CPI)".

\section{Tinjauan Pustaka}

Ada sebagian penelitian tentang sistem pendukung keputusan untuk membantu beberapa pihak dalam proses pemgambilan keputusan. Menurut penelitian "Penerapan Metode CPI Pada Pemilihan Hotel" dapat disimpulkan metode yang umum di gunakan dalam proses pengambilan keputusan adalah metode CPI menggunakan pemecahan masalah dengan sistem Multiple Criteria Decision Making (MCDM) yang menentukan urutan atau prioritas dalam analisi multikriteria[4]. Hasil akhir dari penelitian ini adalah terciptanya sistem pendukung keputusan yang menghasilkan informasi mengenai peringkat hotel yang dapat dijadikan tempat referensi untuk tetap memperhatikan beberapa kriteria.

Hasil penelitian "Sistem Pendukung Keputusan Seleksi Calon Penerima Beasiswa Menggunakan Metode Simple Additive Weighting (SAW)" dalam menentukan penerimaan beasiswa, banyak sekali kriteria-kriteria yang harus dimiliki oleh individu sebagai syarat dalam mendapatkan beasiswa[5]. Hasil penelitian ini berupa Aplikasi Sistem Pendukung Keputusan Penerima Beasiswa dengan Metode SAW yang memudahkan bagian kemahasiswaan untuk menyeleksi mahasiswa yang dapat diusulkan untuk mendapatkan beasiswa sama dengan kriteria yang tersedia, semoga makin cepat dan tepat sasaran sesuai yang diharapkan.

2.1. Sistem Pendukung Keputusan

Sistem Pendukung Keputusan (SPK) merupakan aplikasi interaktif berbasis komputer yang mengkombinasikan data dan model matematis untuk membantu proses pengambilan keputusan dalam menangani suatu masalah"[6]. Ada tiga bagian utama dalam sistem pendukung keputusan, yaitu data, model matematis, dan antarmuka pengguna[7]. Bagian utama tersebut adalah :

1. Data yaitu yang digunakan pada SPK adalah data yang diterima dari data warehouse dalam organisasi tersebut. Terkadang data yang dipakai berupa data mart, yakni data dari data warehouse yang telah dikategorikan berdasarkan kebutuhan organisasi. Hal tersebut secara tidak langsung menegaskan bahwa data warehouse merupakan pondasi dalam SPK.

2. Model matematis yaitu bagian untuk menganalisis data yang berada didata warehouse. Model matematis ini akan berupa analisis statistika yang biasa digunakan dalam mengolah data. Model matemat is ini berguna untuk merubah data menjadi informasi dan knowledge yang bertugas untuk pengambilan keputusan.

3. Antar pengguna (user interface) bagian ini yaitu bagian yang secara langsung dilihat dan berkomunikasi dengan end user atau pada hal ini pemegang keputusan. Data yang ditampilkan harus memberikan informasi yang valid, reliable, dan dalam mendukung untuk pengambilan keputusan. Agar dapat memudahkan dalam pengambilan keputusan, data yang ditampilkan biasanya menggunakan berbagai jenis grafik, animasi, atau peta yang berguna untuk melengkapi data yang ada.

2.2. Tahap-Tahap Sistem Pendukung Keputusan

Tahap-tahap yang harus dilalui dalam pengambilan keputusan sebagai berikut :

1. Kegiatan inteligence

Yaitu kegiatan mengamati lingkungan untuk mengetahui kondisi-kondisi yang perlu diperbaiki[10]. Kegiatan ini merupakan tahapan pada perkembangan cara berfikir. Untuk dapat melakukan kegiatan inteligence ini diperlukan sebuah sistem informasi, dimana informasi yang diperlukan ini didapatkan dari kondisi internal maupun eksternal sehingga seorang manajer akan dapat mengambil sebuah keputusan dengan tepat.

2. Kegiatan merancang

Yaitu sebuah kegiatan untuk dapat menemukan, mengembangkan, dan menganalisa berbagai alternatif tindakan yang mungkin untuk dilakukan. Tahap perancangan ini meliputi pengembangan dan mengevaluasi serangkaian kegiatan alternatif. Pertimbangan-pertimbangan utama telah diperkenalkan oleh Simon untuk melakukan tahapan ini, apakah situasi keputusan ini terprogram atau tidak.

3. Kegiatan memilih dan menelaah

Yaitu digunakan untuk memilih satu rangkaian tindakan tertentu dari bagian-bagian yang tersedia dan melakukan penilaian terhadap tindakan yang telah dipilih.

2.3. Tujuan Sistem Pendukung Keputusan

Tujuan Sistem pendukung keputusan yaitu sebagai berikut :

1. Mendukung manajer pada saat pengambilan keputusan tentang masalah semiterstruktur. 
2. Memberikan dorongan tentang penilaian manajer dan bukannya dimaksudkan untuk menggantikan fungsi manajer.

3. Meningkatkan efektifitas keputusan yang diambil manajer bertambah dari pada perbaikan efisiensinya.

4. Kecepatan komputasi, komputer mengizinkan para pengambil keputusan dapat melakukan banyak komputasi secara cepat dengan biaya yang rendah.

5. Dukungan Kapasitas. Komputer boleh meningkatkan kapasitas keputusan yang dibuat[8].

\section{Metode Penelitian}

Metode Composite Performance Index (CPI) yaitu indeks gabungan (Composite Index) yang akan dapat digunakan untuk menetukan penilaian atau peringkat dari berbagai alternatif berdasarkan beberapa kriteria[9]. Prosedur pada CPI disebutkan sebagai berikut :

a. Identifikasi kriteria tren yaitu positif (semakin tinggi nilainya semakin baik) dan tren negatif (semakin rendah nilainya semakin baik).

b. Untuk kriteria tren positif, nilai minimum pada setiap kriteria ditransformasi secara proporsional lebih tinggi.

c. Untuk kriteria tren negatif, nilai minimum pada setiap kriteria ditransformasi keseratus, sedangkan nilai lainnya ditransformasi secara proporsional lebih rendah.

d. Perhitungan nilai alternatif merupakan jumlah dari perkalian antara nilai kriteria dengan bobot kriteria.

e. Normalisasi matrix dilakukan dengan menyesuaikan Nilai Kriteria dengan Nilai Bobot yang sudah ditentukan.

Index gabungan (Composite Performance) dapat digunakan untuk menetukan penilaian atau peringkat dari berbagai alternatif (i) berdasarkan beberapa kriteria (j).

$$
\begin{aligned}
& A_{i j}=X_{i j}(\min ) \times 100 / X_{i j}(\min ) \\
& A(i+1 . j)=\left(X(I+1 . j) / X_{i j}(\min ) \times 100\right. \\
& I_{i j}=A_{i j} x P_{j} \\
& I_{i}=\ldots
\end{aligned}
$$

Keterangan :

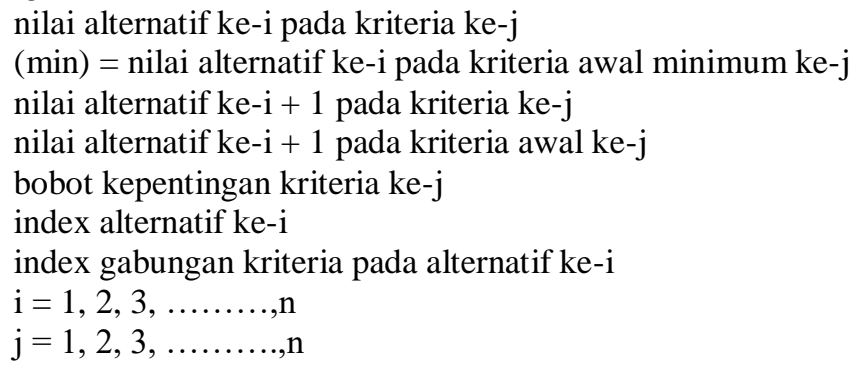

Studi Kasus Pada : Pemilihan Guru Teladan disajikan dalam kriteria dan bobot

Tabel 1. Kriteria dan Bobot

\begin{tabular}{|c|l|c|}
\hline Kriteria & \multicolumn{1}{|c|}{ Keterangan } & Bobot \\
\hline $\mathrm{C}_{1}$ & Kemampuan bidang study & $35 \%$ \\
\hline $\mathrm{C}_{2}$ & Tanggung jawab & $25 \%$ \\
\hline $\mathrm{C}_{3}$ & Kreatifitas & $25 \%$ \\
\hline $\mathrm{C}_{4}$ & Komunikasi & $15 \%$ \\
\hline
\end{tabular}

Tabel 2 terdapat 5 Alternatif yang akan diseleksi untuk mendapatkan Guru Teladan. 
Tabel 2. Alternatif

\begin{tabular}{|c|l|c|c|c|c|}
\hline No & \multicolumn{1}{|c|}{ Nama } & $\mathrm{C}_{1}$ & $\mathrm{C}_{2}$ & $\mathrm{C}_{3}$ & $\mathrm{C}_{4}$ \\
\hline 1 & M.Ikbal Pulungan $\left(\mathrm{A}_{1}\right)$ & 75 & 60 & 80 & 55 \\
\hline 2 & Nur Sakinah Tanjung $\left(\mathrm{A}_{2}\right)$ & 65 & 70 & 50 & 80 \\
\hline 3 & Putri Dani Adelina Hsb $\left(\mathrm{A}_{3}\right)$ & 70 & 80 & 60 & 65 \\
\hline 4 & Anggun $\left(\mathrm{A}_{4}\right)$ & 50 & 60 & 50 & 75 \\
\hline 5 & Martina Klarasia $\left(\mathrm{A}_{5}\right)$ & 60 & 70 & 60 & 80 \\
\hline
\end{tabular}

Data pada Tabel Alternatif diubah kedalam matriks keputusan X dengan data :

$$
X=\left(\begin{array}{llll}
0,25 & 0,25 & 0,35 & 0,15 \\
0,25 & 0,25 & 0,15 & 0,35 \\
0,25 & 0,35 & 0,25 & 0,25 \\
0,15 & 0,25 & 0,15 & 0,25 \\
0,25 & 0,25 & 0,25 & 0,35
\end{array}\right)
$$

1. Perhitungan nilai Kemampuan Bidang Studi

Tren pada Kriteria Kemampuan Bidang Studi adalah (+), dimana semakin tinggi nilai, akan semakin baik.

Tren $(+)=$ Nilai N / Nilai min x 100

$$
\begin{aligned}
& 75: 50=1,5 \times 100=150 \\
& 65: 50=1,3 \times 100=130 \\
& 70: 50=1,4 \times 100=140 \\
& 50: 50=1 \times 100=100 \\
& 60: 50=1,2 \times 100=120
\end{aligned}
$$

Tabel 3. Penghitungan Nilai Kemampuan Bidang Studi

\begin{tabular}{|c|c|c|c|c|}
\hline No & Alternatif & Kemampuan Bidang Studi & N / Min & N / Min x 100 \\
\hline 1 & $\mathrm{~A}_{1}$ & 75 & 1,5 & 150 \\
\hline 2 & $\mathrm{~A}_{2}$ & 65 & 1,3 & 130 \\
\hline 3 & $\mathrm{~A}_{3}$ & 70 & 1,4 & 140 \\
\hline 4 & $\mathrm{~A}_{4}$ & 50 & 1 & 100 \\
\hline 5 & $\mathrm{~A}_{5}$ & 60 & 1,2 & 120 \\
\hline
\end{tabular}

2. Perhitungan Nilai Tanggung Jawab

Tren pada Kriteria kemampuan Bidang Studi adalah (+), dimana semakin tinggi nilai, akan semakin baik. Tren $(+)=$ Nilai N / Nilai $\min \times 100$

$$
\begin{aligned}
& 60: 60=1 \times 100=100 \\
& 70: 60=1,1 \times 100=110 \\
& 80: 60=1,3 \times 100=130 \\
& 60: 60=1 \times 100=100 \\
& 70: 60=1,1 \times 100=11
\end{aligned}
$$

Tabel 4. Penghitungan Nilai Tanggung Jawab

\begin{tabular}{|c|c|c|c|}
\hline Alternatif & Tanggung Jawab & N / Min & Min / N x 100 \\
\hline $\mathrm{A}_{1}$ & 60 & 1 & 100 \\
\hline $\mathrm{A}_{2}$ & 70 & 1,1 & 110 \\
\hline $\mathrm{A}_{3}$ & 80 & 1,3 & 130 \\
\hline $\mathrm{A}_{4}$ & 60 & 1 & 100 \\
\hline $\mathrm{A}_{5}$ & 70 & 1,1 & 110 \\
\hline
\end{tabular}

3. Perhitungan Nilai Kreatifitas

Tren pada Kriteria Kemampuan Kreatifitas adalah (-), dimana semakin tinggi nilai, akan semakin baik.

Tren (-) = Nilai Min / Nilai N x 100 


$$
\begin{aligned}
& 50: 80=0,6 \times 100=60 \\
& 50: 50=1 \times 100=100 \\
& 50: 60=0,8 \times 100=80 \\
& 50: 50=1 \times 100=100 \\
& 50: 60=0,8 \times 100=80
\end{aligned}
$$

Tabel 5. Penghitungan Nilai Kreatifitas

\begin{tabular}{|c|c|c|c|}
\hline Alternatif & Kreatifitas & Min / N & Min / N x 100 \\
\hline $\mathrm{A}_{1}$ & 80 & 0,6 & 60 \\
\hline $\mathrm{A}_{2}$ & 50 & 1 & 100 \\
\hline $\mathrm{A}_{3}$ & 60 & 0,8 & 80 \\
\hline $\mathrm{A}_{4}$ & 50 & 1 & 100 \\
\hline $\mathrm{A}_{5}$ & 60 & 0,8 & 80 \\
\hline
\end{tabular}

4. Perhitungan Nilai Komunikasi

Tren pada Kriteria Kemampuan Komunikasi adalah (-), dimana semakin tinggi nilai, akan semakin baik.

Tren (-) = Nilai Min / Nilai N x 100

$$
\begin{aligned}
& 55: 55=1 \times 100=100 \\
& 55: 80=0,6 \times 100=60 \\
& 55: 65=0,8 \times 100=80 \\
& 55: 75=0,7 \times 100=70 \\
& 55: 80=0,6 \times 100=60
\end{aligned}
$$

Tabel 6. Penghitungan Nilai Komunikasi

\begin{tabular}{|c|c|c|c|}
\hline Alternatif & Komunikasi & Min / N & N / Min x 100 \\
\hline $\mathrm{A}_{1}$ & 55 & 1 & 100 \\
\hline $\mathrm{A}_{2}$ & 80 & 0,6 & 60 \\
\hline $\mathrm{A}_{3}$ & 65 & 0,8 & 80 \\
\hline $\mathrm{A}_{4}$ & 75 & 0,7 & 70 \\
\hline $\mathrm{A}_{5}$ & 80 & 0,6 & 60 \\
\hline
\end{tabular}

5. Penghitungan CPI

CPI $=$ nilai_kriteria_ $1 *$ bobot + nilai_kriteria_ $2 *$ bobot + nilai_kriteria_ $3 *$ bobot + nilai_kriteria_ $4 *$ bobot + nilai_kriteria_5*bobot

Penghitungan $\mathrm{A}_{1}$

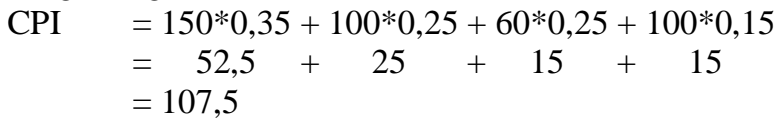

Penghitungan $\mathrm{A}_{2}$

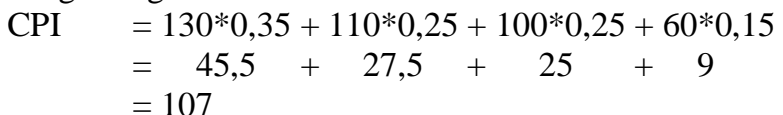

Penghitungan $\mathrm{A}_{3}$

$$
\begin{aligned}
\mathrm{CPI} & =140 * 0,35+130 * 0,25+80 * 0,25+80 * 0,15 \\
& =49+32,5+20+12 \\
& =113,5
\end{aligned}
$$

Penghitungan $\mathrm{A}_{4}$

$$
\begin{aligned}
\text { CPI } & =100 * 0,35+100 * 0,25+100 * 0,25+70 * 0,15 \\
& =35+25+25+10,5 \\
& =95,5
\end{aligned}
$$

Penghitungan $\mathrm{A}_{5}$

$$
\begin{aligned}
\mathrm{CPI} & =120 * 0,35+110 * 0,25+80 * 0,25+60 * 0,15 \\
& =42+27,5+20+9 \\
& =98,5
\end{aligned}
$$

Berikut ini adalah tabel hasil perhitungan CPI berdasarkan peringkat. 
Tabel 7. Hasil Perangkingan CPI

\begin{tabular}{|c|c|c|}
\hline Alternatif & Nilai CPI & Peringkat \\
\hline $\mathrm{A}_{3}$ & 113,5 & 1 \\
\hline $\mathrm{A}_{1}$ & 107,5 & 2 \\
\hline $\mathrm{A}_{2}$ & 107 & 3 \\
\hline $\mathrm{A}_{5}$ & 98,5 & 4 \\
\hline $\mathrm{A}_{4}$ & 95,5 & 5 \\
\hline
\end{tabular}

Penerapan CPI dari 5 ke alternatif diatas menghasilkan $\mathrm{A}_{3}>\mathrm{A}_{1}>\mathrm{A}_{2}>\mathrm{A}_{5}>\mathrm{A}_{4}$, sehingga diputuskan bahwa $\mathrm{A}_{3}$ merupakan guru teladan.

\section{Hasil dan Pembahasan}

1. Flowchart Form Data Nilai

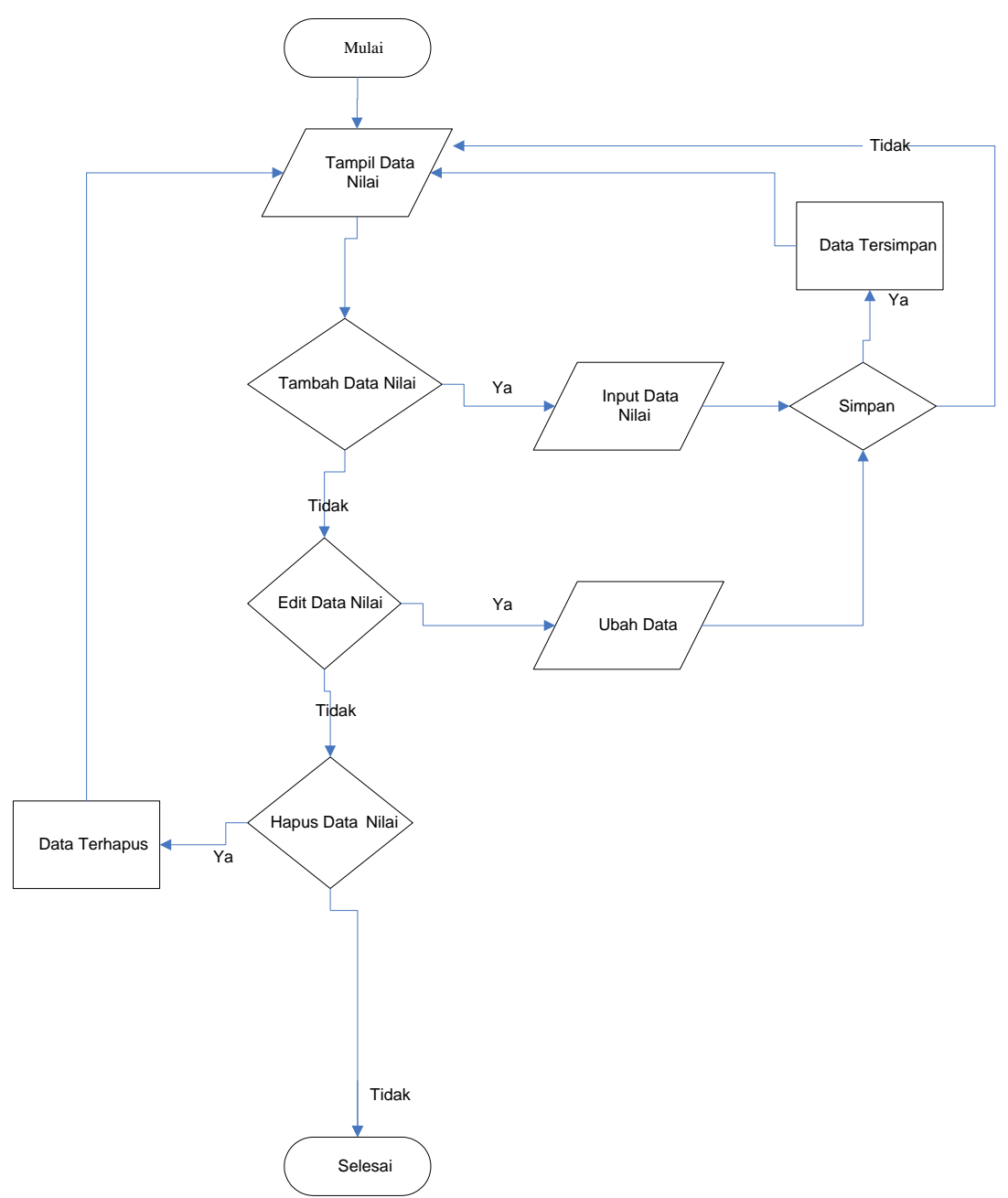

Gambar 1. Flowchart Form Data Nilai. 
2. Flowgraph Form Data Nilai

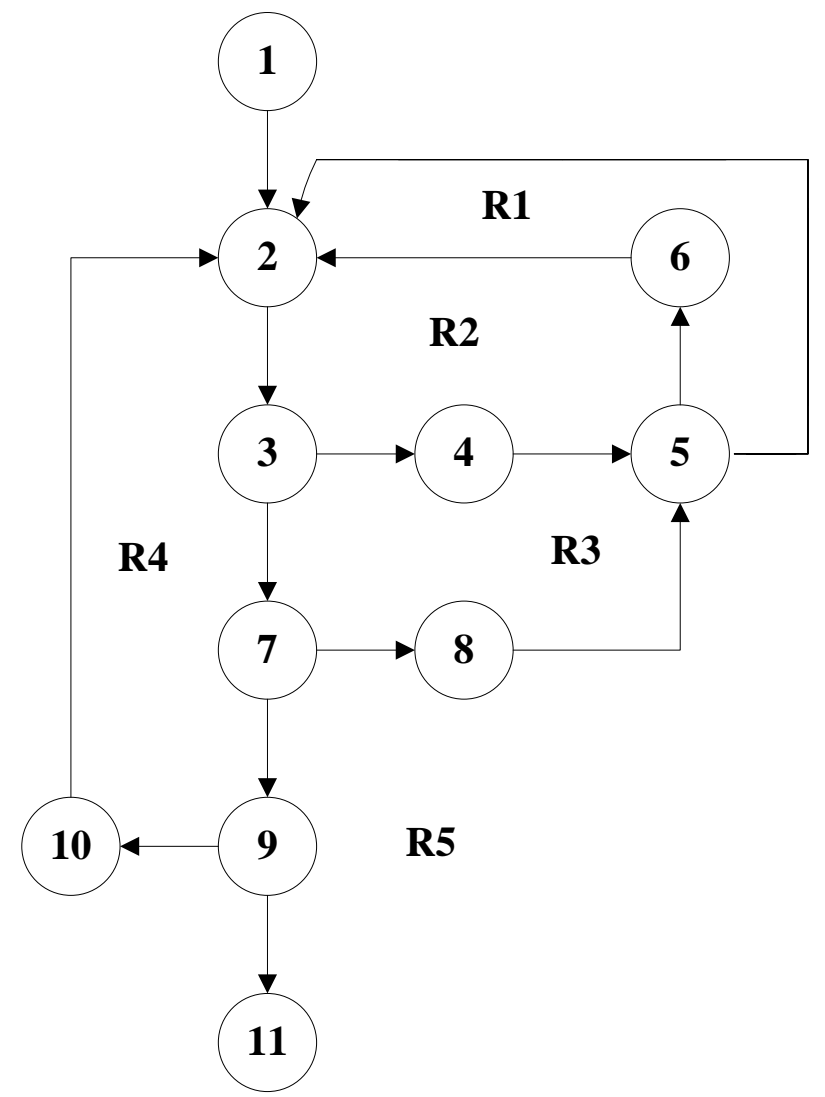

Gambar 2. Flowgraph Form Data Nilai

- Menghitung nilai cyclomatic complexity (CC)

Dimana :

Node $(\mathrm{N})=11$

Edge $(\mathrm{E})=14$

Predicate Node $(\mathrm{P})=4$

Region $(\mathrm{R})=5$

$\mathrm{V}(\mathrm{G})=\mathrm{E}+\mathrm{N}-2$

$$
=14+11-2
$$

Cyclomatic Complexity $(\mathrm{CC})=5$

$\mathrm{V}(\mathrm{G})=\mathrm{P}+1$

$$
=4+1
$$

Cyclomatic Complexity $(\mathrm{CC})=5$

3. Tampilan Form Login Admin

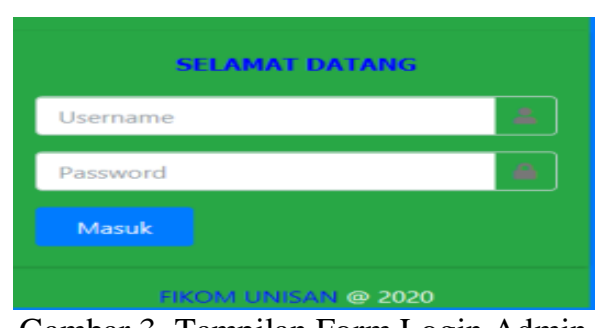

Gambar 3. Tampilan Form Login Admin

Pada form login diatas, pengguna mengisi username dan password untuk masuk kehalaman Sistem 
Pendukung Keputusan Seleksi Beasiswa Prestasi Miskin Pada Dinas Pendidikan Kabupaten Pohuwato. Dimana pengguna mengisi username dengan nama "admin" dan password "admin". Namun jika dalam mengisi username dan password terjadi kesalahan maka akan tampil kembali form login, selanjutnya ulang kembali.

4. Tampilan Halaman Utama

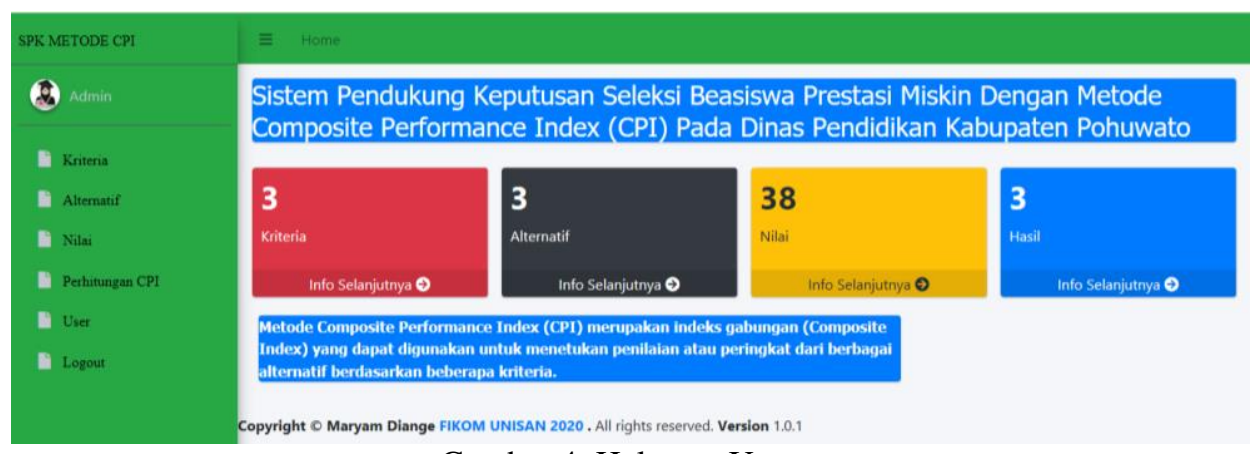

Gambar 4. Halaman Utama

Pada halaman utama ini terdapat menu-menu utama yang ada dalam Sistem Pendukung Keputusan Seleksi Beasiswa Prestasi Miskin Pada Dinas Pendidikan Kabupaten Pohuwato. Halaman ini terdiri atas menu-menu yang akan digunakan untuk menginput data-data untuk Seleksi Beasiswa Prestasi Miskin. Halaman menumenu ini terdiri atas halaman Home, Kriteria, Alternatif, Nilia, Perhitungan CPI, User, dan Logout.

5. Tampilan Tambah Data Kriteria

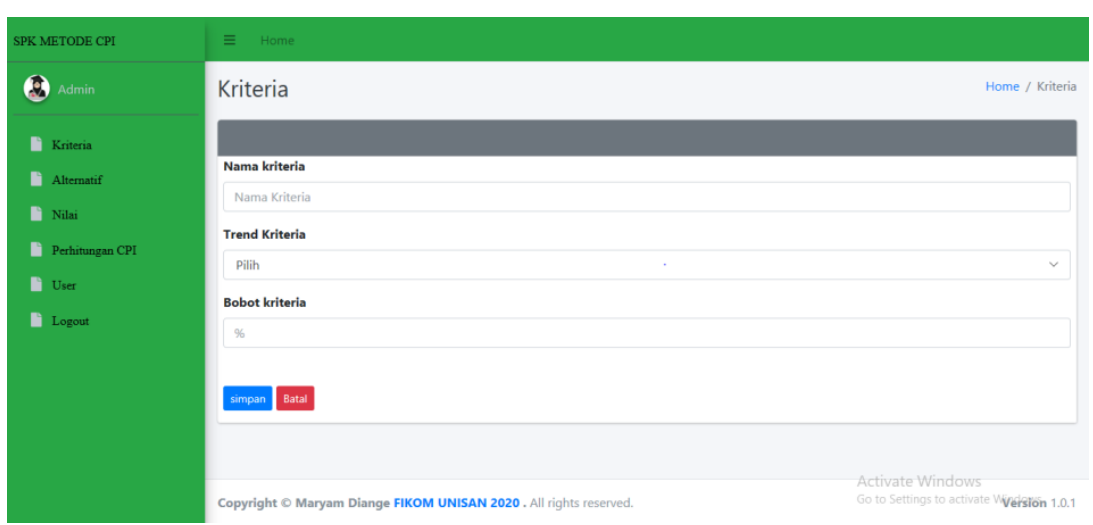

Gambar 5. Tambah Data Kriteria

Tampilan ini guna menginput bahan buat Seleksi Beasiswa Prestasi Miskin. Dalam penginputan data yang akan dinilai klik tambah data, kemudian isi data nama kriteria, pilih data tren kriteria, isi data bobot kriteria, kemudian klik tombol simpan data agar data yang dinputkan dapat tersimpan dan jika tidak ingin menyimpan data maka klik tombol batal.

6. Tampilan Data Kriteria

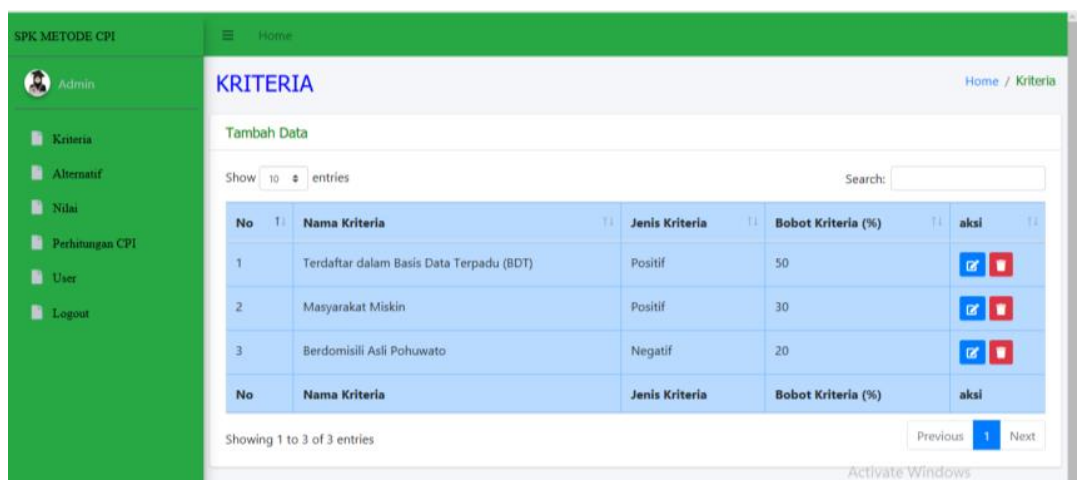

Gambar 6. Data Kriteria 
Halaman ini guna akan menampilkan data kriteria, jenis kriteria, dan bobot kriteria Seleksi Beasiswa Prestasi Miskin yang telah diinput.

7. Tampilan Tambah Data Alternatif

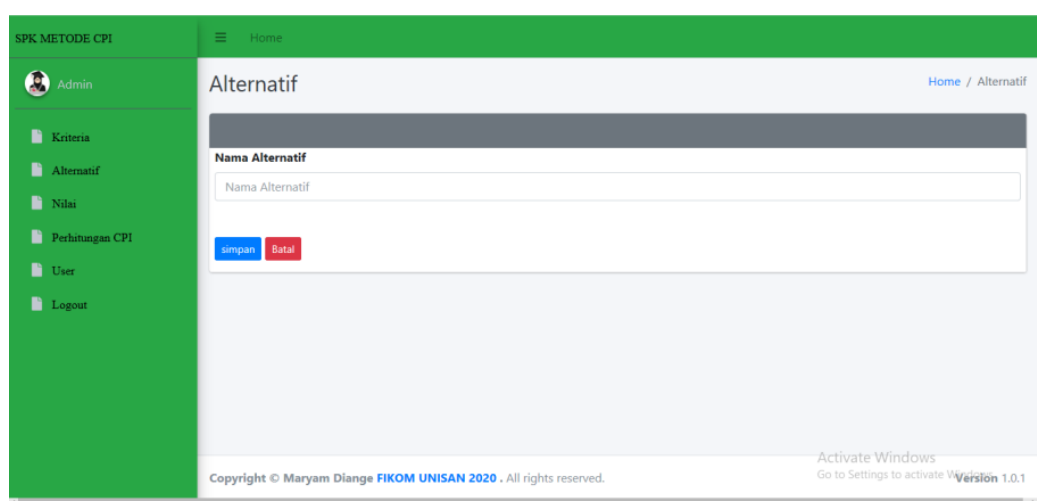

Gambar 7. Tampilan Tambah Data Alternatif

Tampilan tambah data alternatif digunakan untuk menginput data Seleksi Beasiswa Prestasi Miskin. Untuk penginputan data alternatif klik tambah data, kemudian isi data nama alternatif, kemudian klik tombol simpan agar data yang diinputkan dapat tersimpan dan jika tidak ingin menyimpan data maka klik tombol batal. 8. Tampilan Data Alternatif

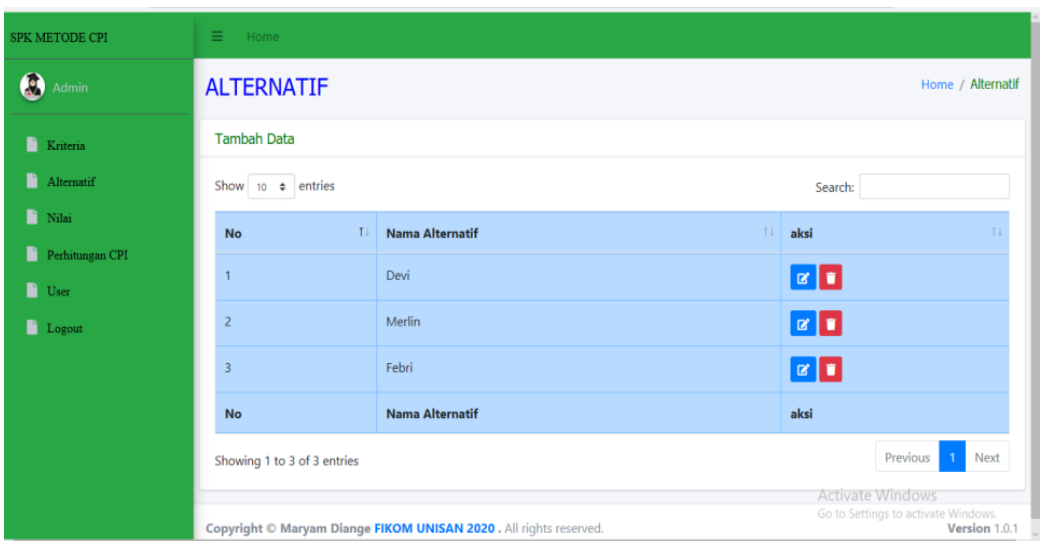

Gambar 8. Tampilan Data Alternatif

Tampilan ini digunakan untuk menampilkan data alternatif Seleksi Beasiswa Prestasi Miskin yang telah diinput.

9. Tampilan Tambah Data Nilai

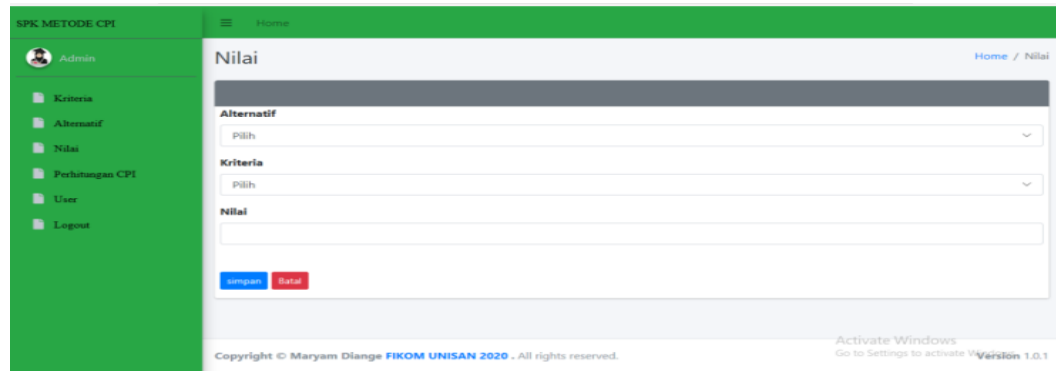

Gambar 9. Tampilan Tambah Data Nilai

Tampilan ini digunakan untuk menginput data nilai yang akan digunakan dalam Seleksi Beasiswa Prestasi Miskin. Untuk penginputan data yang akan dihitung klik tambah data kemudian klik pilih alternatif, selanjutnya klik pilih kriteria, dan input nilai. Kemudian klik tombol simpan agar data yang diinputkan dapat tersimpan 
dan jika tidak ingin menyimpan data maka klik tombol batal.

10. Tampilan Data Nilai

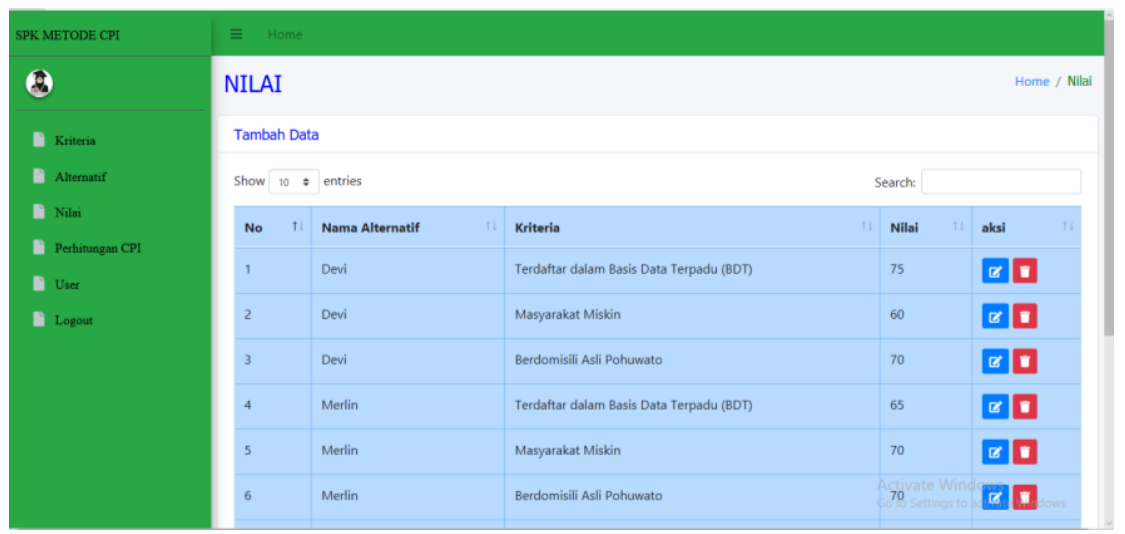

Gambar 10. Tampilan Data Nilai

Tampilan ini menampilkan data nilai yang terdapat nama alternatif, kriteria, dan nilai untuk Seleksi Beasiswa Prestasi Miskin.

11. Tampilan Ubah Data Nilai

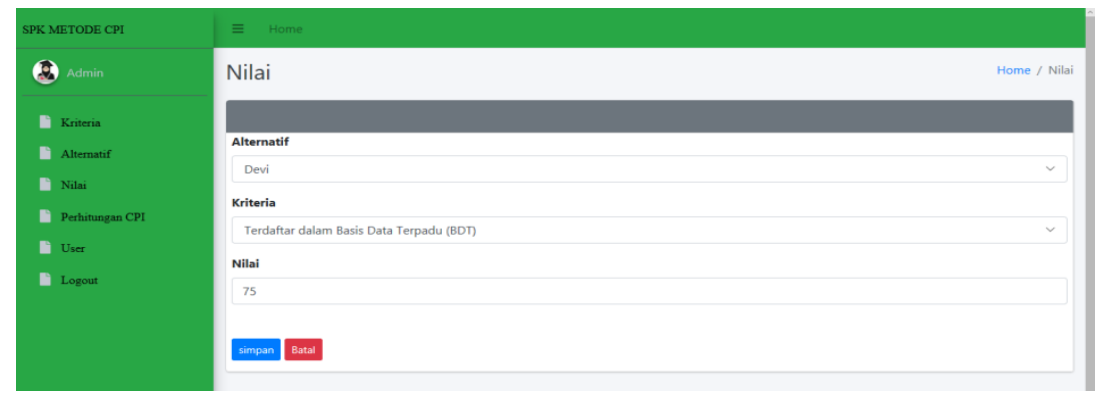

Gambar 11 Tampilan Ubah Data Nilai

Tampilan ini menampilkan ubah data nilai, dalam mengubah data klik edit data yang berada pada samping kanan kemudian input data alternatif, kriteria, dan nilai. Kemudian klik tombol simpan agar data yang diinputkan dapat tersimpan dan jika tidak ingin menyimpan data maka klik tombol batal.

12. Tampilan Data Matrik Perbandingan Berpasangan (X)

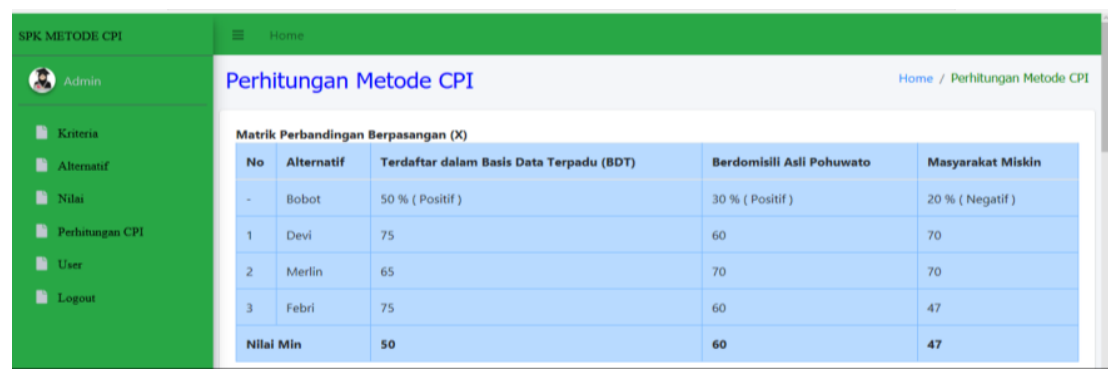

Gambar 12. Tampilan Data Matrik Perbandingan Berpasangan (X)

Tampilan ini digunakan untuk menampilkan data perhitungan matrik perbandingan berpasangan (x) yang terdiri dari Alternatif, Terdaftar dalam Basis Data Terpadu (BDT), Berdomisili Asli Pohuwato, dan Masyarakat Miskin yang digunakan dalam Seleksi Beasiswa Prestasi Miskin.

13. Tampilan Data Bobot Kepentingan (P) dan Tren 


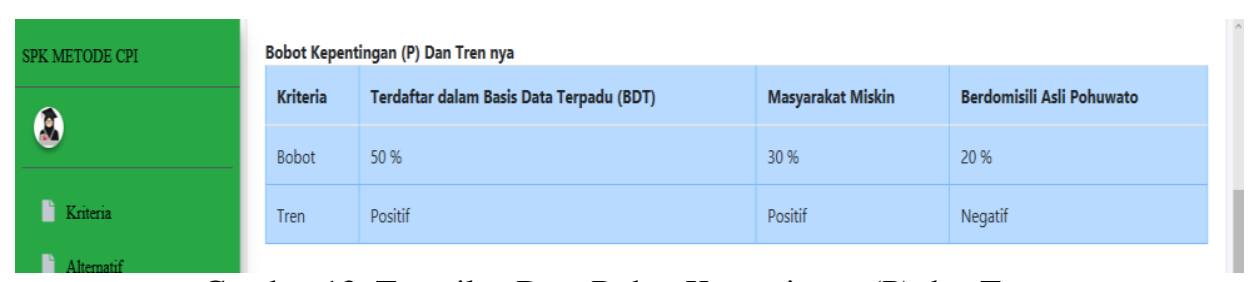

Gambar 13. Tampilan Data Bobot Kepentingan (P) dan Tren

Tampilan ini digunakan untuk menampilkan data bobot kepentingan (p) dan trennya yang terdiri dari Kriteria, Terdaftar dalam Basis Data Terpadu (BDT), Berdomisili Asli Pohuwato, dan Masyarakat Miskin sedangkan trennya terdiri atas Positif dan Negatif yang digunakan dalam Seleksi Beasiswa Prestasi Miskin. 14. Tampilan Hasil Perhitungan Nilai Terdaftar dalam (BDT)
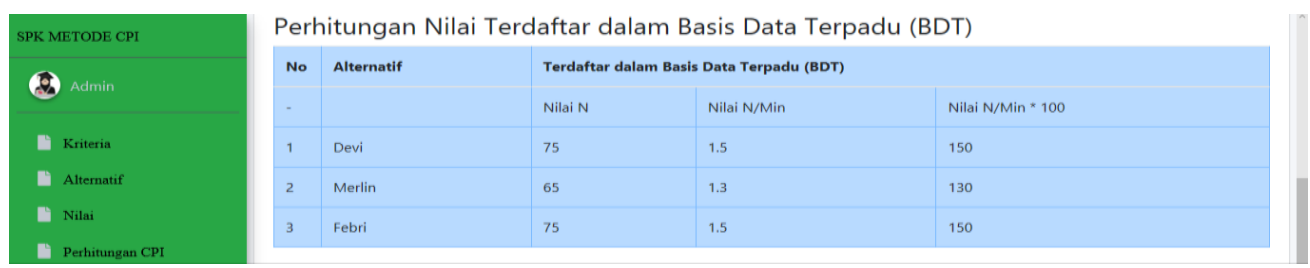

Gambar 14. Tampilan Hasil Perhitungan Nilai (BDT)

Tampilan ini digunakan untuk menampilkan hasil perhitungan nilai yang terdaftar dalam Basis Data Terpadu (BDT) pada proses pemberian Beasiswa Prestasi Miskin yang berdasarkan pada penilaian yang telah diinputkan terlebih dahulu.

15. Tampilan Hasil Perhitungan Nilai Masyarakat Miskin

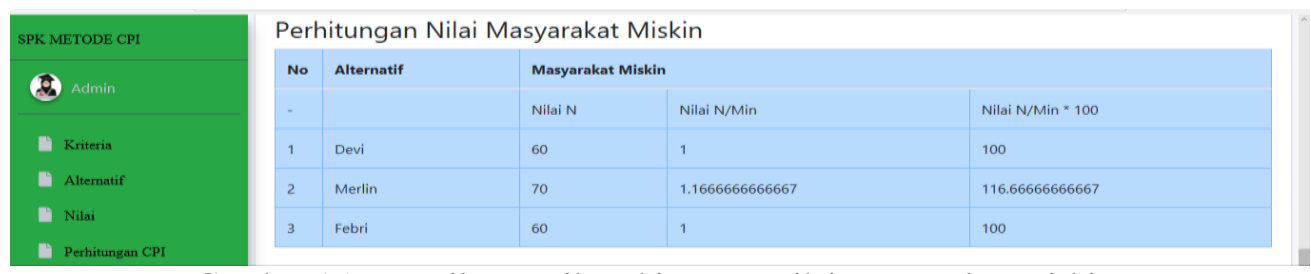

Gambar 15. Tampilan Hasil Perhitungan Nilai Masyarakat Miskin

Tampilan ini digunakan untuk menampilkan hasil perhitungan yang termasuk dalam masyarakat miskin dalam proses pemberian Beasiswa Prestasi Miskin yang berdasarkan pada penilaian yang telah diinputkan terlebih dahulu.

16. Tampilan Hasil Perhitungan Nilai Berdomisili Asli Pohuwato

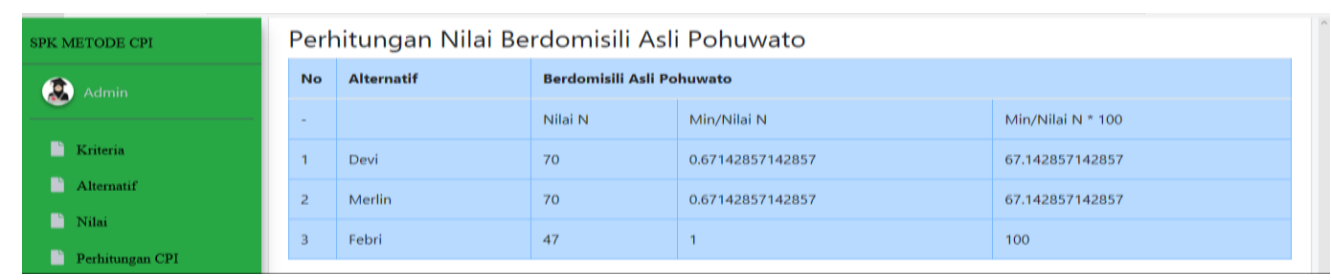

Gambar 16. Tampilan Hasil Perhitungan Nilai Berdomisili Asli Pohuwato

Tampilan ini digunakan untuk menampilkan hasil perhitungan yang termasuk pada berdomisili asli pohuwato dalam proses pemberian Beasiswa Prestasi Miskin yang berdasarkan pada penilaian yang telah diinputkan terlebih dahulu. 
17. Tampilan Hasil Perhitungan CPI

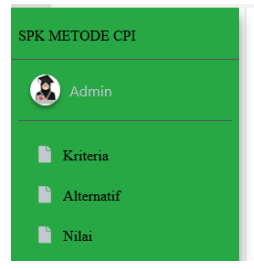

Perhitungan CPI

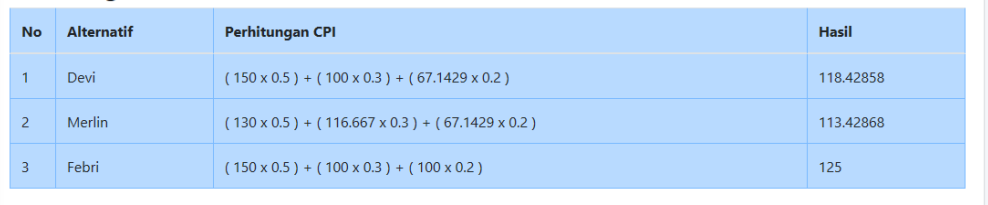

Gambar 17 Tampilan Hasil Perhitungan CPI

Tampilan ini digunakan untuk menampilkan hasil perhitungan Cpi yang terdapat Alternatif, Perhitungan Cpi, dan Hasil yang digunakan dalam Seleksi Beasiswa Prestasi Miskin.

18. Tampilan Hasil Rangking
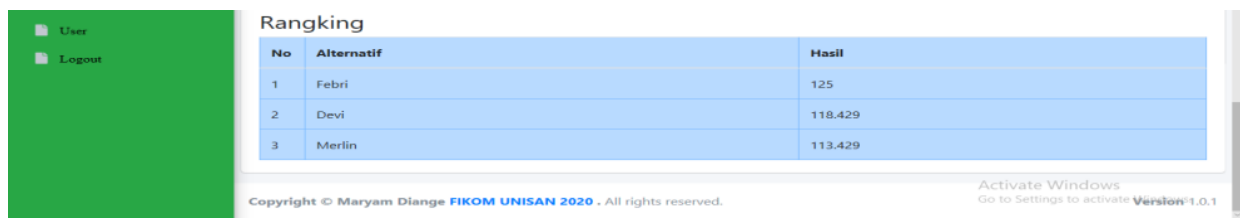

Gambar 18. Tampilan Hasil Rangking

Tampilan menu rangking digunakan untuk menampilkan hasil akhir atau tampilan data perangkingan dalam Seleksi Beasiswa Prestasi Miskin Pada Dinas Pendidikan Kabupaten Pohuwato.

\section{Kesimpulan}

1. Sistem pendukung keputusan yang digunakan bisa mengatasi kelemahan-kelemahan yang ada dalam sistem terdahulu. Sistem pendukung keputusan dapat memberikan hasil maksimal dalam hal pengambilan keputusan.

2. Dilihat dari perolehan pengujian white box, penulis menyimpulkan maka dilihat dari sistem pendukung keputusan ini akan bebas melalui suatu kesalahan program. Peristiwa ini dibuktikan dengan hasil pengujian yang dilakukan dengan metode pengujian White Box Testing dan Basis Path yang menghasilkan nilai $\mathrm{V}(\mathrm{G})=$ Cyclomatic Complexity $=5$.

3. Pengembangan SDM (Sumber Daya Manusia) sangat dibutuhkan agar sistem dapat berjalan lebih optimal. Adapun untuk lebih menyempurnakan penelitian ini, peneliti mengharapkan terhadap peneliti selanjutnya agar bisa dapat memberikan hal-hal yang baru demi untuk bisa berkembangnya penelitian ini, beserta dengan memperhatikan ketentuan kriteria yang pada saat akan digunakan untuk proses seleksi.

\section{Daftar Pustaka}

[1] Alhamidi. 2016. Membangun Sstem Aplikasi Untuk Seleksi Calon Mahasiswa Undangan Pada Tingkat Sekolah Menengah Atas. Jurnal J-Click Vol. 3 No. 2 Desember 2016 : 54

[2] Dewi Silvia Mega. 2012. Penggunaan Aplikasi Adobe Photoshop Dalam Meningkatkan Keterampilan Editing Foto Bagi Anak Tunarungu. Jurnal Ilmiah Pendidikan Khusus Vol. 1 No. 2 Mei 2012 : 261-263

[3] Dzulhaq Iqbal Muhammad and Imani Rian. 2015. Sistem Pendukung Keputusan Pemilihan Konsentrasi Jurusan Menggunakan Fuzzy Inferrence Sistem Metode Mamdani. Jurnal Sisfotek Global Vol. 5 No. 2 September $2015: 76$

[4] Erfina. 2012. Desain Sistem Secara Umum : (https://erfina-coding.blogspot.com/2012/06/desain-sistemsecara-umum.html?=1 diakses 26 Maret 2020)

[5] Fadli Sofiansyah and Imtihan Khairul. 2018. Analisis Dan Perancangan Sistem Administrasi Dan Transaksi Berbasis Client Server. Jurnal Informatika Dan Rekayasa Elektronika Vol. 1 No. 2 November $2018: 8-9$

[6] Fatchan Muhamad. 2017. Perancangan Dan Implementasi Sistem Ekspor Impor Pada PT. Dawee Electronic Indonesia. Jurnal Teknologi Pelita Bangsa Vol. 7 No. 1 September 2017 : 55

[7] Firman Astria. et al. 2016. Sistem Informasi Perpustakaan Online Berbasis Web. Jurnal Teknik Elektro dan Komputer Vol. 5 No. 2 Januari-Maret $2016: 30$

[8] Gunawan Hendra. et al. 2018. Sistem Pendukung Keputusan Seleksi Calon Penerima Beasiswa Menggunakan Metode Simple Additive Weighting. Jurnal Informasi Vol. X No. 2 November $2018: 21$ 
[9] Ismail S. M. et al. 2016. Rancang Bangun Sistem Informasi Terpadu FMIPA Universitas Tadulako. Jurnal Ilmiah Matematika dan Terapan Vol. 13 No. 1 Juni $2016: 19$.

[10] L. Situmorang and J. R. Sagala, "Sistem Pendukung Keputusan Pemilihan Tentor Terbaik Dengan Metode Technique For Order Preference By Similarity To Ideal Solution (Topsis)," J. Nas. Komputasi dan Teknol. Inf., vol. 3, no. 3, pp. 209-214, 2020. 